\title{
Catabolic Response Profiles, Catabolic Uniformity and Richness as Microbiological Indicators in a Soil of Pergamino, Buenos Aires Province, with and without Previous Application of Glyphosate
}

\author{
Ruth P. Ríos, Lidia Giuffré, Romina I. Romaniuk*, Mónica G. Pérez, Eduardo A. Pagano \\ School of Agriculture, University of Buenos Aires, Buenos Aires, Argentina \\ Email:epagano@agro.uba.ar
}

Received 10 March 2016; accepted 9 May 2016; published 12 May 2016

Copyright $(\underset{2016}{ } 20 y$ authors and Scientific Research Publishing Inc.

This work is licensed under the Creative Commons Attribution International License (CC BY). http://creativecommons.org/licenses/by/4.0/

(c) () Open Access

\begin{abstract}
Incubation assay in trays was performed with two soils with different application histories of glyphosate: no application, and previous application. The soils used were Typic Argiudolls of Pergamino, province of Buenos Aires, and the treatments were: control (no application), and 20, 200 and $2000 \mathrm{mg}$ of active ingredient per $\mathrm{kg}$ of soil. Sampling was performed at the beginning (T0) and 45 days after (T45). Catabolic response profiles (CRP), catabolic richness and catabolic uniformity were determined according to the methodology based on measuring the differences in respiration induced by substrate in a short time ( 4 hours). The substrates used in this study were 20, namely, two amines, 5 aminoacids, two carbohydrates, and 11 carboxylic acids. The objective of this work was to compare soils with different histories of application of glyphosate, measuring its effect on catabolic response profiles, catabolic uniformity and catabolic richness. In this study, no differences were observed between catabolic richness among the different sampling times and doses of glyphosate applied. Glyphosate application affected the structure of the soil microbial communities. At the end of the test, soils with all doses of previous herbicide application showed greater catabolic uniformity than soils without previous application.
\end{abstract}

\section{Keywords}

Glyphosate, Catabolic Response Profiles, Catabolic Uniformity and Richness

\footnotetext{
"INTA Castelar, Buenos Aires.
}

How to cite this paper: Ríos, R.P., et al. (2016) Catabolic Response Profiles, Catabolic Uniformity and Richness as Microbiological Indicators in a Soil of Pergamino, Buenos Aires Province, with and without Previous Application of Glyphosate. Journal of Agricultural Chemistry and Environment, 5, 85-91. http://dx.doi.org/10.4236/jacen.2016.52009 


\section{Introduction}

Concerns about long-term agricultural sustainability and the high environmental costs of conventional cropping practices have made imperative to develop soil and crop management practices that improve soil and environmental health [1].

Soil ecosystems are highly complex, containing a tremendous amount of species. Indigenous microbial populations in soil are of fundamental importance for ecosystem functioning, through determining nutrient cycling, organic matter decomposition, energy flow [2], and the formation and stabilization of soil structure [1]. According to Zhou et al. [3], the various physiological groups of microorganisms change with depth, and play an important role in soil formation.

Crecchio et al. [2] state that despite all attempts to measure fluxes and gross microbial pools, the soil and its microbiota still remain a black box. Most soil microorganisms are still unknown, while very few have been isolated, cultured and identified, and directly related to their function in agroecosystems.

New approachments have evolved from microbiological determinations such as microbial biomass and respiration coefficients towards the investigation of bacterial diversity and microbial communities structure, but Graham et al. [4] propose that direct measurements of functional diversity of soil microbial communities are likely to provide information more relevant to the functioning of soils than measurements of species diversity or community structure. This is largely because microorganisms are often present in soil in resting or dormant stages that are not functionally active.

Liu et al. [5] consider that soil microbial community functional diversity is mainly controlled by resource availability in temperate steppes at a regional scale.

It has also been shown that agricultural management practices (e.g., tillage, crop rotation, and irrigation) strongly influence the soil environment and, consequently, the size, composition, and function of the microbial community in soils [1]. Land degradation can cause great changes in the soil biological properties, the process may decrease soil microbial biomass and consequently decrease soil microbial activity [6].

Stevenson et al. [7] use the CRP (catabolic response profiles) approach, and the microbial community diversity has been shown to respond to changes in land use, and stress or disturbance to the soil. They report that pasture soils have significantly greater responses than forest soils, to aminoacid and carbohydrate groups and the individual substrates L-arginine, L-asparagine, D-glucose, quinic acid, L-serine, and uric acid.

Bortoli et al. [8] suggest that the impact of glyphosate on microbial biomass and activity can be related to previous application and soil type, in soils of Argentina under olive plantations.

The objective of this work is to analyze application of glyphosate in Argiudolls from Pergamino (Buenos Aires province, Argentina) in samples with and without previous application of glyphosate, measuring its effect on catabolic response profiles, catabolic uniformity and catabolic richness.

\section{Materials and Methods}

Incubation assay in trays was performed with two soils with no application (SG) and previous application (CG) of glyphosate. The soils used were Typic Argiudolls of Pergamino, province of Buenos Aires. The contamination consisted of a single application of commercial glyphosate (Roundup) in three doses of active ingredient. Treatments consisted of control (no application), and 20, 200 and $2000 \mathrm{mg}$ of active ingredient per kg of soil.

The lowest value represents a commonly recommended dose for field applications, while the higher dose would represent a case of contamination.

The trays consisted of $500 \mathrm{~g}$ of soil placed under controlled conditions of $25^{\circ} \mathrm{C}$.

Sampling was performed at baseline (T0) and at 45 days after starting the test (T45).

Catabolic response profiles (CRP) were determined according to the methodology proposed by Degens and Harris [9], which relies on measuring the differences in substrate-induced respiration in a short time (4 hours) to amino acid addition to the soil of carboxylic acids, carbohydrates and organic polymers. The substrates used in this study were 20, namely, two amines (D-glucosamine, L-glutamine), 5 aminoacids (L-arginine, L-glutamic, L-histidine, L-lysine and L-serine), two carbohydrates (D-glucose and D-mannose), and 11 carboxylic acids (Lascorbic, citric, gluconic, ketobutaric, $\alpha$-ketoglutaric, DL-malic, malonic, pantothenic, quinic, tartaric and uric).

Respiration, measured as $\mathrm{CO}_{2}$ emitted per unit mass of soil, was determined by gas chromatography. From these measurements the catabolic uniformity (UC), was calculated through the diversity index proposed by Simpson-Yule [10]: 


$$
\begin{gathered}
E=\frac{1}{\sum p_{i}^{2}} \\
p_{i}=\frac{r_{i}}{\sum r_{i}}
\end{gathered}
$$

$r_{i}=$ respiration measured for each substrate.

The results were analyzed with analysis of variance and multiple comparisons using Duncan's test.

\section{Results and Discussion}

\section{Catabolic Response Profiles}

Catabolic response profiles for all treatments at baseline (T0) and 45 days of pollution (T45) are presented (Figure 1). In both sampling times all substrates were metabolized with no differences between treatments at both sampling times. A general trend in the preferential metabolism of the carboxylic substrates over carbohydrates, amines and amino acids is observed.

\section{1-Comparison between doses in soils with previous application of glyphosate at T0}

The soil with previous applications of glyphosate, when the doses of 20, 200 and $2000 \mathrm{mg}$ of active ingredient per kg of soil are applied, showed increases of catabolic uniformity compared to control (Table 1). This means that the different functional groups of soil microorganisms using glyphosate as a substrate for microbial communities were adapted to the degradation of the herbicide, increasing microbial activity, corroborating the findings of Wardle and Parkinson [11] and Haney et al. [12]. The catabolic diversity of microbial communities was
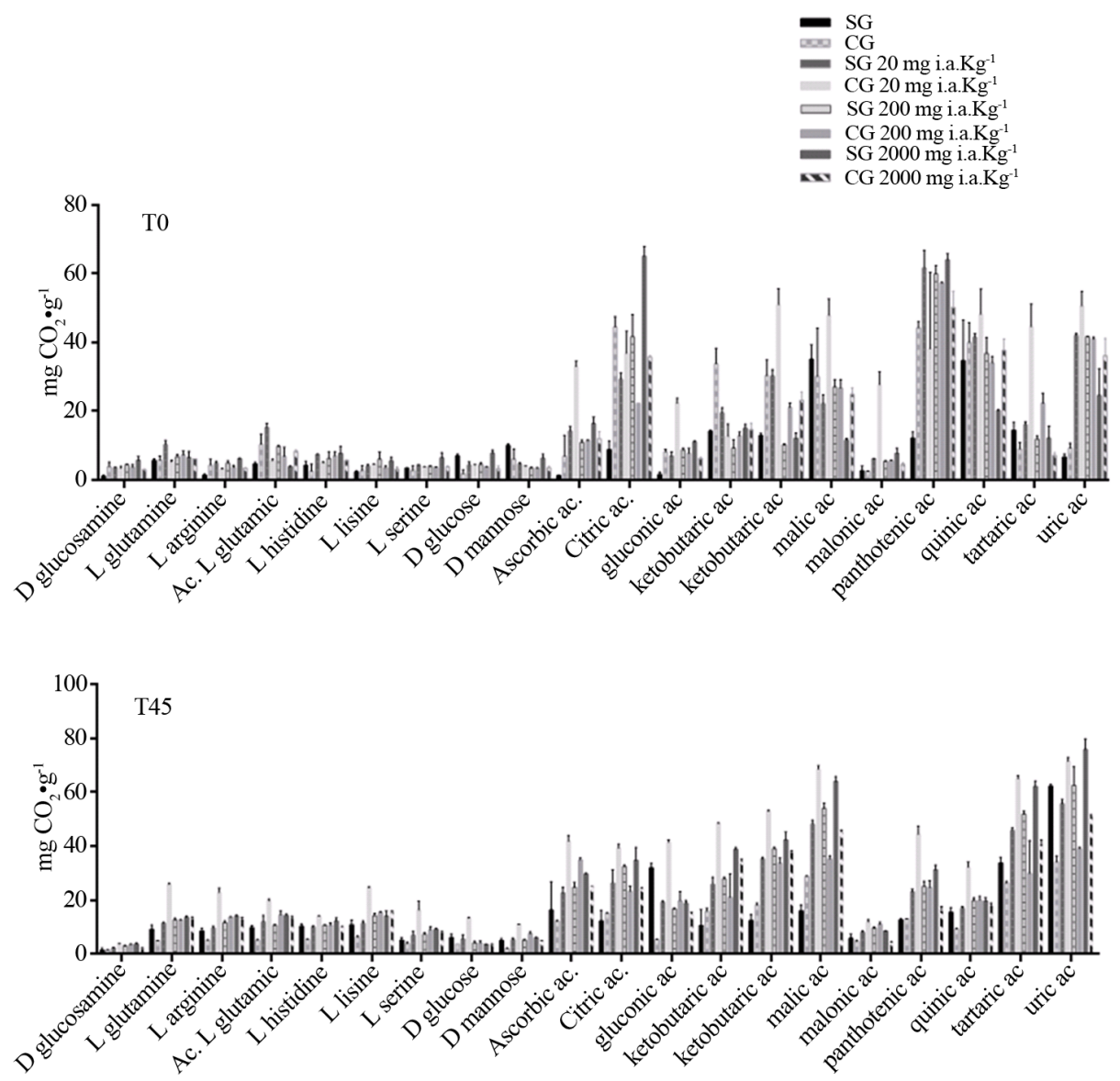

Figure 1. Catabolic response profiles for a: T0 and b: T 45, different dosage, in SG (without previous application of glyphosate), and CG (with previous application of gliphosate). 
Table 1. ANOVA for catabolic uniformity in T0, tratment CG, variable UC, with Duncan Test, $\alpha=0.05$.

\begin{tabular}{ccccc}
\hline Dose & Mean & $\mathrm{n}$ & S.E. & \\
\hline 0 & 8.84 & 3 & 0.35 & A \\
20 & 10.96 & 3 & 0.35 & B \\
200 & 10.29 & 3 & 0.35 & B \\
2000 & 10.30 & 3 & 0.35 & B \\
\hline
\end{tabular}

not affected by the application rate and there were no statistically significant differences between the different doses of glyphosate.

2-Comparison between doses in soils without previous application of glyphosate at T0

Soil with no previous application of glyphosate increased biological activity only at low doses (20) (Table 2). However, at higher doses of glyphosate, biological activity is not increased and this may perhaps be due to a harmful effect on soil microorganisms or lack of adaptation to the degradation of the herbicide. According to Ractiliff et al., [13], cited by Bozzo [14], the effects of glyphosate are highly transient and dose dependent, and it could be explained by the rapid growth of opportunistic bacteria that utilize the compounds as a source of nutrients and/or carbon. The effect is that applications at field dose or second dose of glyphosate have no effect or little effect on soil microbial communities.

\section{3-Comparison between doses in soils with previous application of glyphosate in T45}

At 45 days post pollution, all tratments contaminated with glyphosate have higher levels of catabolic uniformity compared to control (Table 3). This means that soil biological activity was enhanced by the presence of glyphosate. This is consistent with the findings of Haney et al. [12] and Busse et al. [15], who concluded that microbial activity was stimulated in the presence of glyphosate. Ratcliff et al. [13] found that the application of glyphosate caused increased functional diversity, particularly in clay-loam soils. Furthermore, Araujo et al. [16] demonstrated that soils with previous applications of glyphosate showed a strong response of the microbial activity with a new application of the herbicide.

The lowest rates of glyphosate (20 and 200) presented the largest stimulation of the catabolic diversity, while higher doses had a higher catabolic uniformity statistically significant when compared to control, but it was lower than the lowest dose used. This could be due to a selection effect at high doses of the herbicide causing alteration in the composition of soil microbial communities as components that can selectively stimulate some microbian community over others, as suggested by Wardle and Parkinson [17] and Busse et al. [15].

\section{4-Comparison between doses in soils without previous application of glyphosate in T45}

For the soil without glyphosate application record, all doses of glyphosate showed statistically significantly greater catabolic uniformity value than control, but did not differ from each other (Table 4). That is, at 45 days after application of the herbicide, the biological activity of different functional groups of soil microorganisms is stimulated, regardless of the applied dose.

The lack of adaptation of microorganisms to the use of glyphosate as a carbon source resulted in no statistically significant differences between doses, showing differences with soil CG at T45.

5-Comparison between soils with and without previous application of glyphosate herbicide for all doses at T0 and T45 (Figure 2)

At T0, no statistically significant differences were found for the same doses between soils with different histories of glyphosate application. This means that the previous application had no effect on the catabolic uniformity of soil microorganisms.

At T0, there were no statistically significant differences between soils with and without previous glyphosate application, regardless of the applied dose.

For control soil, there were no significant differences in the catabolic uniformity of microorganisms between soils with and without previous glyphosate application at 45 days after application. However, comparing soils with and without previous application of the same dose, this study found that, for all doses tested, soils with previous application of glyphosate had greater catabolic uniformity than those with no application. Also, previous application showed an increase in the functional diversity of soil microorganisms, suggesting that in these soils, the prior application of herbicide acted selecting heterotrophic microbial communities capable of using glyphosate as a substrate. 
(a)
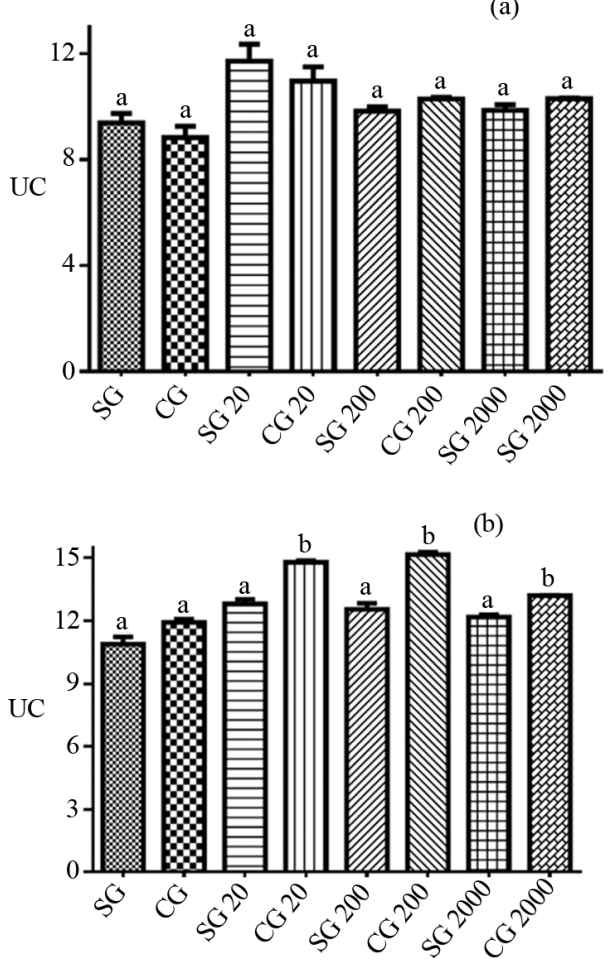

Figure 2. Catabolic uniformity (UC) for SG and CG. a: T0 , b: T45.

Table 2. ANOVA for catabolic uniformity in T0, tratment SG, variable UC, with Duncan Test, $\alpha=0.05$.

\begin{tabular}{ccccc}
\hline Dose & Mean & $\mathrm{n}$ & S.E. & \\
\hline 0 & 9.39 & 3 & 0.47 & $\mathrm{~A}$ \\
20 & 11.72 & 3 & 0.47 & $\mathrm{~B}$ \\
200 & 9.93 & 3 & 0.47 & $\mathrm{~A}$ \\
200 & 9.19 & 3 & 0.47 & $\mathrm{~A}$ \\
\hline
\end{tabular}

Table 3. ANOVA for catabolic uniformity in T45, tratment CG, variable UC, with Duncan Test, $\alpha=0.05$.

\begin{tabular}{ccccc}
\hline Dose & Mean & $\mathrm{n}$ & S.E. & \\
\hline 0 & 11.93 & 3 & 0.10 & $\mathrm{~A}$ \\
20 & 14.80 & 3 & 0.10 & $\mathrm{C}$ \\
200 & 15.16 & 3 & 0.10 & $\mathrm{D}$ \\
2000 & 13.21 & 3 & 0.10 & $\mathrm{~B}$ \\
\hline
\end{tabular}

Table 4. ANOVA for catabolic uniformity in T45, tratment SG, variable UC, with Duncan Test, $\alpha=0.05$.

\begin{tabular}{ccccc}
\hline Dose & Mean & $\mathrm{n}$ & S.E. & \\
\hline 0 & 10.88 & 3 & 0.26 & A \\
20 & 12.81 & 3 & 0.26 & B \\
200 & 12.55 & 3 & 0.26 & B \\
2000 & 12.18 & 3 & 0.26 & B \\
\hline
\end{tabular}


This corroborates the findings of Araujo et al. [16] in studies that evaluated glyphosate in soils without prior glyphosate, and other areas with 6-11 years of herbicide application. They observed increased production of carbon dioxide in those soils with previous herbicide application. Soils exposed to glyphosate for several years had higher microbial activity. They concluded that this phenomenon was due to the fact that applications may have selected microbial populations capable of utilizing the herbicide.

\section{Discussion}

Microbial communities can provide useful data to study both applied and basic environmental events, so maintaining soil microbial biomass and micro-flora activity and diversity is fundamental for sustainable agricultural management [18].

Biological, especially microbiological attributes such as biomass and activities, are sensitive to soil management practices. Modifications in biological properties may precede detectable changes in soil physical and chemical properties and thus provide an early signal of improvement or a warning of degradation [19].

An understanding of the main factors influencing microbial diversity in soils is necessary to predict the effects of current land-use trends on terrestrial diversity.

Differences in catabolic uniformity between pasture and other land-uses on matched soils were related to differences in organic carbon pools. Although the implications of this for microbial processes are unknown, maintenance of soil organic carbon may be important for preservation of microbial diversity [20].

The soil microorganisms at different depths play an important role in soil formation, ecosystem biogeochemistry, recycling of nutrients, and degradation of waste products. Zhou et al. [3] found that microbial metabolic diversity was different at every depth, so it could be a new challenge to repeat studies not only with surface horizon.

Bortoli et al. [8] found that, in general, the soil without prior glyphosate application had a greater impact on microbial community. The application of high concentrations of glyphosate may alter the activity and structure of soil microbial communities, although this effect was less pronounced and consistent at lower concentrations.

\section{Conclusions}

The present work showed that there were no differences between catabolic richness among the different sampling times and doses of glyphosate applied. Glyphosate application affected the structure of the soil microbial communities, and it had a greater impact on catabolic uniformity in soils without prior glyphosate application.

At the end of the test, all doses of the applied treatments with previous herbicide application showed greater catabolic uniformity than soils without previous application.

\section{References}

[1] Kong, A.Y., Scow, K.M., Córdova-Kreylos, A.L., Holmes, W.E. and Six, J. (2011) Microbial Community Composition and Carbon Cycling within Soil Microenvironments of Conventional, Low-Input, and Organic Cropping Systems. Soil Biology \& Biochemistry, 43, 20-30. http://dx.doi.org/10.1016/j.soilbio.2010.09.005

[2] Crecchio, C., Gelsomino, A., Ambrosoli, R., Minati, J.L. and Ruggiero, P. (2004) Functional and Molecular Responses of Soil Microbial Communities under Differing Soil Management Practices. Soil Biology \& Biochemistry, 36, 18731883. http://dx.doi.org/10.1016/j.soilbio.2004.05.008

[3] Zhou, J., Guo, W., Wang, R., Han, X. and Wang, Q. (2008) Microbial Community Diversity in the Profile of an Agricultural Soil in Northern China. Journal of Environmental Sciences, 20, 981-988. http://dx.doi.org/10.1016/S1001-0742(08)62197-X

[4] Graham, M.H. and Haynes, R.J. (2005) Catabolic Diversity of Soil Microbial Communities under Sugarcane and Other Land Uses Estimated by Biolog and Substrate-Induced Respiration Methods. Applied Soil Ecology, 29, 155-164. http://dx.doi.org/10.1016/j.apsoil.2004.11.002

[5] Liu, Z., Fu, B., Zheng, X. and Liu, G. (2010) Plant Biomass, Soil Water Content and Soil N:P Ratio Regulating Soil Microbial Functional Diversity in a Temperate Steppe: A Regional Scale Study. Soil Biology \& Biochemistry, 42, 445450. http://dx.doi.org/10.1016/j.soilbio.2009.11.027

[6] Nunes, J.S., Araujo, A.S.F., Nunes, L.A.P.L., Lima, L.M., Carneiro, R.F.V., Salviano, A.A.C. and TSA, S.M. (2012) Impact of Land Degradation on Soil Microbial Biomass and Activity in Northeast Brazil. Pedosphere, 22, 88-95. http://dx.doi.org/10.1016/S1002-0160(11)60194-X 
[7] Stevenson, B.A., Sparling, G.P., Schipper, L.A., Degens, B.P. and Duncan, L.C. (2004) Pasture and Forest Soil Microbial Communities Show Distinct Patterns in Their Catabolic Respiration Responses at a Landscape Scale. Soil Biology \& Biochemistry, 36, 49-55. http://dx.doi.org/10.1016/j.soilbio.2003.08.018

[8] Bórtoli, P.V, Verdenelli, R.A., Conforto, C., Vargas, Gil, S. and Meriles, J.M. (2012) Efectos del herbicida glifosato sobre la estructura y el funcionamiento de comunidades microbianas de dos suelos de plantaciones de olivo. Ecología Austral, 22, 33-42.

[9] Degens, B.P., Schipper, L.A., Sparling, G.P. and Vojvodic-Vukovic, M. (2000) Decreases in Organic C Reserves in Soils Can Reduce the Catabolic Diversity of Soil Microbial Communities. Soil Biology \& Biochemistry, 32, 189-196. http://dx.doi.org/10.1016/S0038-0717(99)00141-8

[10] Magurran, A.E. (1988) Ecological Diversity and Its Measurements. Croom Helm, London. http://dx.doi.org/10.1007/978-94-015-7358-0

[11] Wardle, D. and Parkinson, D. (1990) Effects of Three Herbicides on Soil Microbial Biomass and Activity. Plant and Soil, 122, 21-28. http://dx.doi.org/10.1007/BF02851906

[12] Haney, R., Senseman, S., Hons, E. and Zuberer, D. (2000) Effect of Glyphosate on Soil Microbial Activity and Biomass. Weed Science, 48, 89-93. http://dx.doi.org/10.1614/0043-1745(2000)048[0089:EOGOSM]2.0.CO;2

[13] Ratcliff, A.W., Busse, M.D. and Shestak, C.J. (2006) Changes in Microbial Community Structure Following Herbicide (Glyphosate) Additions to Forest Soils. Applied Soil Ecology, 34, 114-124. http://dx.doi.org/10.1016/j.apsoil.2006.03.002

[14] Bozzo, A. (2010) Persistencia del glifosato y efecto de sucesivas aplicaciones en el cultivo de soja en agricultura continua en siembra directa sobre parámetros Biológicos del suelo. Trabajo de tesis de maestría en Ciencias Ambientales. Universidad de la República_Facultad de Ciencias, 124.

[15] Busse, M., Ratcliff, A., Shestak, C. and Powers, R. (2001) Glyphosate Toxicity and the Effects of Long-Term Vegetation Control on Soil Microbial Communities. Soil Biology and Biochemistry, 33, 1777-1789. http://dx.doi.org/10.1016/S0038-0717(01)00103-1

[16] Araújo, A., Monteiro, R. and Abarkeli, R. (2003) Effect of Glyphosate on the Microbial Activity of Two Brazilian Soils. Elsevier Science, 52, 799-804. http://dx.doi.org/10.1016/S0045-6535(03)00266-2

[17] Wardle, D. and Parkinson, D. (1992) The Influence of the Herbicide Glyphosate on Interspecific Interactions between Four Fungal Species. Mycology Research, 96, 180-186. http://dx.doi.org/10.1016/S0953-7562(09)80963-5

[18] Bram Govaerts, B., Mezzalama, M., Unno, Y., Sayre, K.D., Luna-Guido, M., Vanherck, K., Dendoov, L. and Deckers, J. (2007) Influence of Tillage, Residue Management, and Crop Rotation on Soil Microbial Biomass and Catabolic Diversity. Applied Soil Ecology, 37, 18-30. http://dx.doi.org/10.1016/j.apsoil.2007.03.006

[19] Gomez, E., Ferreras, L. and Toresani, S. (2006) Soil Bacterial Functional Diversity as Influenced by Organic Amendment Application. Bioresource Technology, 97, 1484-1489. http://dx.doi.org/10.1016/j.biortech.2005.06.021

[20] Degens, B.P., Schipper, L.A., Sparling, G.P. and Vojvodic-Vukovic, M. (2000) Decreases in Organic C Reserves in Soils Can Reduce the Catabolic Diversity of Soil Microbial Communities. Soil Biology \& Biochemistry, 32, 189-196. http://dx.doi.org/10.1016/S0038-0717(99)00141-8 